\title{
ANALISIS TINGKAT KESEGARAN JASMANI ANGGOTA UKM BOLABASKET UNIVERSITAS TEKNOKRAT INDONESIA
}

\author{
Adityo Pratama ${ }^{1}$, Rizki Yuliandra ${ }^{2}$ \\ Universitas Teknokrat Indonesia ${ }^{\mathbf{1 , 2}}$ \\ teyoadit@gmail.com ${ }^{1}$ \\ rizki.yuliandra@teknokrat.ac.id ${ }^{2}$
}

\begin{abstract}
Received: 5 Mei 2020
Accepted: 30 Mei 2020

Abstract

Physical fitness is one of the important components in doing any activities. The sport activity is closely related to the achievements that cannot be separated from several factors and one of them is physical fitness. Related to this issue, the physical fitness of basketball club members in Universitas Teknorat Indonesia has not been known yet. Therefore, this study aims to measure the physical fitness level of basketball club members in Universitas Teknorat Indonesia. This study is a qualitative descriptive study by surveying basketball members. The subject of this study is 30 members of basketball club in Universitas Teknorat Indonesia. The data collecting technique used in this study is TKJI instrument consisting of 5 item tests, they are 50-meter run test, pull up, sit up, vertical jump, and run 1,2 KM. Descriptive statistical analysis with percentages is employed in this research as the data analysis technique. The result of this study shows that the physical fitness levels of basketball club members in Universitas Teknorat Indonesia are 26,66\% for 8 members, 53,3\% of medium classification for 16 members, 20,1\% of less classification for 6 members, and none of the members has an excellent and poor classification. Thus, the result of the physical fitness level test for members of basketball club in Universitas Teknorat Indonesia can be categorized at a medium level.
\end{abstract}

Published : 29 Juni 2020

Keywords: Physical Fitness, Test, Run, Push Up, Sit Up, Vertical Jump

\begin{abstract}
Abstrak
Kesegaran jasmani sebagai salah satu komponen yang penting dalam melakukan kegiatan atau aktivitas. Kegiatan berolahraga sangat berkaitan dengan prestasi yang tidak lepas dari beberapa faktor dan salah satu diantaranya adalah Kesegaran Jasmani. Terkait dengan Kesegaran Jasmani yang dimiliki oleh anggota UKM Bolabasket Universitas Teknorat Indonesia belum diketahui. Adapun tujuan penelitian ini adalah untuk mengetahui Tingkat Kesegaran Jasmani anggota UKM Bolabasket Universitas Teknorat Indonesia. Penelitian ini adalah penelitian deskriptif yang menggunakan metode survei. Subyek dari penelitian ini adalah anggota UKM Bolabasket Universitas Teknorat Indonesia, dengan jumlah 30 anggota. Teknik pengambilan data pada penelitian ini menggunakan instrumen TKJI yang terdiri dari 5 item tes yaitu: Tes lari 50 meter, Pull up, Sit Up , Vertical Jump, lari 1,2 KM. Teknik analisis data yang digunakan dalam penelitian ini adalah analisis statistik deskriptif dengan persentase. Hasil penelitian menunjukkan bahwa Tingkat Kebugaran UKM Bolabasket Universitas Teknorat Indonesia yaitu sebanyak 8 orang $(26,66 \%)$, klasifikasi sedang sebanyak 16 orang $(53,33 \%)$, dan klasifikasi kurang sebanyak 6 orang $(20,1 \%)$, dan tidak ada siswa yang memiliki klasifikasi baik sekali dan kurang sekali. Dengan demikian, hasil tes tingkat kesegaran jasmani pada Anggota UKM Bolabasket Universitas Teknokrat Indonesia dapat dikategorikan sedang.
\end{abstract}

Kata Kunci: Kesegaran Jasmani ,Tes,Lari , Push Up, Sit Up, Vertical Jump

\section{To cite this article:}

Pratama, Adityo dan Yuliandra, Rizki. (2020). Analisis Tingkat Kesegaran Jasmani Anggota UKM Bolabasket Universitas Teknokrat Indonesia. Journal Of Physical Education. 1(1), 25-32 


\section{PENDAHULUAN}

Pendidikan jasmani sangat penting di negara berkembang seperti Indonesia, karena baik buruknya pendidikan akan berpengaruh terhadap kemajuan suatu bangsa dan negara. Tujuan dari pendidikan jasmani yaitu menyehatkan tubuh dengan cara berolahraga. Pendidikan jasmani sebagai komponen pendidikan secara pelaksanaan pembelajaraan pendidikan jasmani belum berjalan secara efektif seperti yang diharapkan. Salah satu bagian dari pendidikan yaitu pendidikan jasmani yang merupakan bagian dari pendidikan nasional untuk mempersiapkan manusia-manusia pembangunan yang sehat jasmani dan rohani (Yuliandra, 2017). Menurut Mahfud (2018) bahwa Kegiatan olahraga permainan di sekolah yang diberikan oleh guru-guru bidang studi pendidikan jasmani akan banyak membantu pertumbuhan dan perkembangan anak secara menyeluruh Pendidikan jasmani termasuk sebagai media yang mendorong perkembangan motorik, kemampuan fisik, pengetahuan penalaran, penghayatan nilai (sikap, mental, emosional, spritual, sosial), membantu manusia memahami mengapa tubuh bergerak dan bagaimana cara melakukan gerak secara aman, efisien, efektif sehingga menghargai manfaat aktivitas jasmani bagi peningkatan kualitas hidup dan pembiasaan pola hidup sehat yang bermuara untuk merangsang pertumbuhan dan perkembangan yang seimbang. Di dalam kurikulum pendidikan jasmani siswa diharapkan memiliki Kesegaran Jasmani yang memadai, menguasai paling tidak salah satu nomor atletik, senam, beladiri, renang, dan olahraga permainan sehingga peserta didik mempunyai kepercayaan diri untuk melakukan kegiatan olahraga secara teratur, memiliki gaya hidup aktif karena didukung oleh pengetahuan yang memadai tentang pendidikan jasmani, peraturan teknis dan taktis serta strategi olahraga (Yuliandra, 2018).

Dari penjelasan olahraga di atas terdapat pula ciri-ciri olahraga menurut Lutan (1991) menjelaskan ciri khas olahraga yaitu:

1. Olahraga berorientasi pada kegiatan jasmani dalam wujud keterampilan motorik, daya tahan, kekuatan, dan kecepatan. Dalam olahraga unsur jasmani yang sangat dominan.

2. Olahraga sebagai sebuah realitas, olahraga dilakukan dalam suasana yang tak sebenarnya, tetapi keterlibatan seseorang dalam olahraga merupakan sesuatu yang nyata.

3. Prinsip prestasi dalam olahraga, tanda-tanda prinsip prestasi dalam olahraga ialah:

a. Peragaan kemampuan jasmani, hingga tingkat maksimal.

b. Kegiatan olahraga dilaksanakan secara maksimal.

c. Tidak bertujuan untuk menghancurkan lawan.

4. Aspek sosial dari olahraga, olahraga yang dilakukan akan terjadi sebuah interaksi sosial dan akan membentuk kelompok sosial.

Dalam olahraga, masih banyak dijumpai permasalahan-permasalahan yang di temukan, seperti dalam hal pemahaman para pelatih terhadap bentuk latihan yang tepat dan efektif untuk dipergunakan dalam melatih keterampilan teknik dasar bolabasket. Jelas sangatlah memprihatinkan apabila kondisi semacam itu terus berlanjut, sebab bagaimana seorang pendidik akan dapat merancang model latihan dengan baik (Yuliandra, 2017). Dalam rangka usaha untuk meningkatkan prestasi maksimal pada cabang olahraga yang ditekuni, seorang atlet perlu sekali memperhatikan faktor-faktor penentunya. Faktor-faktor penentu dapat disebutkan ada tiga faktor penting yaitu : kondisi fisik atau tingkat kesegaran jasmani, ketepatan teknik atau ketrampilan yang dimiliki, dan masalah-masalah lingkungan (Gumantan, 2018). Dan dari penjelasan di atas tersebut bisa disimpulkan bahwa olahraga merupakan suatu kegiatan jasmani yang sangat dominan, merupakan sesuatu yang nyata, terdapat prinsip prestasi dan membentuk kelompok sosial. Di dalam kurikulum pendidikan jasmani diharapkan memiliki Kesegaran Jasmani yang memadai, menguasai paling tidak salah satu nomor atletik, senam, beladiri, renang, dan olahraga permainan sehingga peserta didik mempunyai kepercayaan diri untuk melakukan kegiatan olahraga secara teratur, memiliki gaya hidup aktif karena didukung oleh pengetahuan yang memadai tentang pendidikan jasmani, peraturan teknis dan taktis serta strategi olahraga (Yuliandra, 2018).

\section{TELAAH PUSTAKA \\ Kesegaran Jasmani}

Kesegaran Jasmani merupakan satu hal yang dapat mempengaruhi dalam pencapaian prestasi suatu atlet. Kesegaran Jasmani yang tangguh dan baik jika dilatih secara terus menerus akan semakin lebih baik dalam pencapaian prestasi. Kesegaran Jasmani merupakan salah satu aspek dari Komponen Kondisi Fisik . Dimana kondisi fisik merupakan pondasi untuk meraih prestasi bagi semua atlet. Teknik, mental dan taktik akan dapat dikembangkan dengan baik jika memiliki kualitas fisik yang baik. Pendapat yang dikemukakan Sajoto (1988), kondisi fisik adalah satu prasyarat yang sangat diperlukan dalam usaha peningkatan prestasi seorang atlet, 
bahkan dapat dikatakan sebagai dasar landasan titik tolak suatu awalan olahraga prestasi. Kondisi fisik dapat mencapai titik optimal jika dimulai sejak usia dini dan dilakukan secara terus menerus sepanjang tahun dengan berpedoman pada prinsip-prinsip dasar latihan. Di samping itu, perkembangan fisik harus direncanakan secara periodik berdasarkan tahapan latihan, status kondisi fisik atlet, faktor-faktor lain, seperti gizi, fasilitas, alat, lingkungan dan status kesehatan atlet (Fahrizqi, 2019).

Menurut Irianto dalam Nugroho (2020), latihan adalah suatu proses mempersiapkan organisme atlet secara "sistematis" untuk mencapai mutu prestasi maksimal dengan diberi beban fisik dan mental yang teratur, terarah, meningkat, dan "berulang-ulang" waktunya Untuk mencapai Kesegaran Jasmani yang baik seorang atlet harus memiliki komponen dasar dari aspek jasmani. Menurut Irianto (2002) mengemukakan bahwa komponen dasar dari biomotor olahragawan ada 5 yaitu: kekuatan (strength), daya tahan (endurance), kecepatan (speed), kelentukan (flexibility) dan koordinasi (coordination). Adapun komponen-komponen yang lain merupakan perpaduan dari beberapa komponen sehingga membentuk satu peristilahan sendiri. Beberapa komponen kondisi fisik yang diperlukan dan mempengaruhi kemampuan passing atau mengoper bola, diantaranya yaitu panjang tungkai, kekuatan otot tungkai, lingkar paha kekuatan tung kai,dan koordinasi kaki. Berdasarkan uraian di atas peneliti ingin mengetahui tentang kemampuan ketepatan jarak jauh khususnya pula aspek fisiknya (Fahrizqi , 2019).

Dari sepuluh komponen kondisi fisik yang perlu diperhatikan lebih dan ditingkatkan lebih untuk meningkatkan prestasi atlet sepakbola dalam penelitian ini. Sedangkan komponen komponen kondisi fisik yang akan digunakan dalam penelitian ini yaitu: kekuatan yang meliputi, Power otot tungkai,kekuatan ketahanan otot perut, kekuatan dan ketahanan otot lengan, kecepatan (speed), daya tahan aerobik, Dari kelima komponen tersebut dapat dijelaskan sebagai berikut:

1) Kecepatan

Kecepatan sangat berkaitan dengan waktu yang di tempuh. Dalam olahraga sepakbola, kecepatan lari sangat diperlukan untuk mengejar bola dalam menyerang maupun bertahan.

2) Kekuatan dan ketahanan otot kaki

Kekuatan dan ketahanan otot kaki digunakan pada saat menendang, menggiring ,mengumpan,berlari, dalam permainan sepakbola sangat banyak sekali dan sangat diutamakan . kekuatan sangat diperlukan dalam setiap melakukan aktivitas olahraga Kekuatan merupakan komponen yang harus dimiliki oleh setiap pemain sepakbola.

3) Ketahanan dan Kekuatan

Kekuatan adalah kemampuan otot untuk melakukan kontraksi guna membangkitkan ketegangan terhadap suatu ketahanan.

4) Daya Tahan

Daya tahan otot setempat merupakan kemampuan seseorang dalam mempergunakan suatu kelompok ototnya, untuk berkontraksi terus menerus dalam waktu yang relatif cukup lama dengan beban tertentu

\section{Basket}

Bolabasket adalah olahraga yang dimainkan 5 orang untuk setiap regunya dan bola harus dipantulkan sambil berlari atau berjalan, atau dapat dioperkan teman seregunya dengan sasaran akhir yaitu memasukkan bola ke keranjang (basket) lawan. Di samping itu harus berusaha dan menjaga agar keranjang (basket) nya tidak kemasukan bola, serta regu yang mencetak angka (score) terbanyak adalah sebagai pemenang ( Irsyada, 2000).. Dasar bermain bola basket dengan cara lempar tangkap, menggiring dan menembak dengan luas lapangan $28 \mathrm{~m}$ x 15 m dapat terbuat dari tanah, lantai, dan papan yang dikeraskan. Permainan bola basket menggunakan bola yang dapat didorong, ditepuk dengan telapak tangan terbuka, melemparkan, dan menangkap, menggiring ke segala penjuru dalam lapangan permainan. Menurut Sumiyarsono dalam Nugroho (2020), permainan bolabasket yaitu permainan yang di mainkan dengan kemampuan tangan, permainan bolabasket menggunakan bola yang berukuran besar dan permainan bolabasket bertujuan untuk dapat memasukan bola sebanyak-banyaknya kedalam keranjang lawan serta menjaga atau mempertahankan keranjang sendiri dari musuh yang memiliki tujuan yang sama. Pendapat lainnya, Bola Basket adalah permainan beregu yang terdiri dari 2 tim dengan 5 pemain per tim. Tujuannya adalah mendapatkan nilai (score) dengan memasukkan bola ke keranjang dan mencegah tim lain melakukan hal serupa. Bola dapat diberikan hanya dengan passing (operan) dengan tangan atau dengan mendribblenya (batting, pushing, atau tapping) beberapa kali pada lantai tanpa menyentuhnya dengan dua tangan secara bersamaan (Wissel, 2000).

Setiap Teknik gerakan dalam bola basket terdiri dari unsur-unsur gerak yang terkoordinasi dengan baik. Seseorang yang sudah menguasai teknik dalam bola basket dengan benar maka permainan bola basket nya akan 
terlihat indah dan menarik untuk dilihat. Ada beberapa teknik dasar yang terdapat dalam olahraga bola basket. teknik dasar dalam permainan bola basket adalah sebagai berikut:

(1) Mennggiring bola (Dribbling), (2) Menangkap bola (Catching), (3) Mengoper bola (Passing); (a) Dengan dua tangan: Chest pass, Bounce pass, Overhead pass, (b) Dengan satu tangan: Baseball pass, Lob pass, Hook pass, Jump pass, (4) Menembak (Shooting); (a) Menghadap papan (Facing shoot), (b) Membelakangi papan (Back up shoot) (Sumiyarsono, 2002). Pendapat lain membagi teknik dasar bola basket menjadi 7 macam yakni: (1) Footwork (gerakan kaki), (2) Shooting (menembak), (3) Passing (operan) dan menangkap, (4) Dribble, (5) Rebound, (6) Bergerak dengan bola, (7) Bergerak tanpa bola, dan (8) Bertahan (Wissel,1996).

Peraturan-peraturan bola basket dibuat untuk para pelatih, pemain, petugas, dan lain-lain dengan tidak membedakan jenis kelamin laki-laki atau perempuan. Hal ini harus dimengerti bahwa semata-mata permainan Bola Basket dilakukan hanya untuk kepentingan kesehatan. Peraturan permainan yang berlaku ialah peraturan permainan yang dikeluarkan oleh FIBA dan juga disahkan oleh PERBASI (Dinata, 2006).

Bola basket memiliki sejarah yang cukup panjang di Indonesia. Tercatat sejak tahun 1930-an, walau belum resmi menjadi sebuah negara yang merdeka, beberapa kota di Indonesia telah memiliki klub-klub lokalnya sendiri. Walaupun belum memiliki induk olahraga nasional, pada saat penyelenggaraan Pekan Olahraga Nasional pertama yang diadakan di Solo pada tahun 1948, bola basket telah menjadi salah satu cabang olahraga yang dipertandingkan dan mendapat sambutan cukup meriah baik dari segi peserta maupun penonton. Kompetisi bolabasket resmi tingkat nasional di kelola oleh Perbasi. Liga Bola Basket Indonesia (nama resmi: Indonesian Basketball League, disingkat IBL) adalah liga bola basket tertinggi yang dikelola secara profesional di Indonesia yang diatur oleh Perbasi dan diikuti oleh 12 klub peserta dari seluruh Indonesia. Liga ini dimulai pada tahun 2003 dengan nama Indonesian Basketball League (IBL). Pada tahun 2010, Perbasi menunjuk (DBL) Indonesia untuk menangani kompetisi ini dan mengubah namanya menjadi National Basketball Indonesia (NBL Indonesia). Setelah berakhirnya kontrak Perbasi dengan PT Deteksi Basket Lintas (DBL) pada tahun 2015 dilanjutkan kesepakatan kontrak yang baru dengan Starting 5, nama kompetisi ini kembali menjadi Indonesian Basketball League dan menggunakan format pertandingan yang baru.

Dari penjelasan dan pendapat diatas, permainan bola basket adalah salah satu olahraga yang didasarkan pada kemampuan individual, kerja sama tim, kecepatan, kekuatan, dan daya tahan. Tim atau regu yang berhasil memasukkan bola lebih banyak lah yang menjadi pemenang. Untuk bisa memainkan bola basket dengan baik, diperlukan kemampuan yang cukup. Maka diperlukan suatu latihan yang rutin, disiplin, kemauan yang kuat, teknik latihan yang tepat untuk mewujudkan kemampuan tersebut.

\section{UKM Bolabasket Teknokrat}

UKM Bolabasket Universitas Teknokrat Indonesia dibentuk pada tahun 2007 , dibentuknya UKM agar tersalurnya bakat serta prestasi mahasiswa pada saat itu. Terbentuknya UKM Bolabasket Universitas Teknokrat Indonesia menjadi wadah tersendiri untuk para atlet atau mahasiswa yang memang memiliki ketertatikan serta kemampuan dalam permainan Bolabasket. UKM Bolabasket Universitas Teknokrat Indonesia telah memiliki banyak Prestasi khusunya di lingkup provinsi sumatera bagian selatan. Banyak kejuaraan yang telah diikuti dan banyak pula prestasi yang telah diukir oleh UKM bolabasket Universitas Teknokrat Indonesia . Salah satunya menjadi Juara pada kejuaraan Bolabasket Se Sumatera yang diadakan di Padang tahun 2014. Di provinsi lampung sendiri UKM Bolabasket Universitas Teknokrat Indonesia Sudah Sering Mengikuti Kejuaraan yang diadakan Baik oleh Pemerintah Provinsi maupun Universitas lainnya. Untuk Tingkat Nasional Prestasi terakhir yang pernah diikuti yakni menjadi Peserta Nasional pada kejuaraan Pekan Olahraga Mahasiswa Nasional di Makasar tahun 2017 dan Di Jakarta tahun 2019.

Dari penjelasan Kajian Teori diatas dapat disimpulakan Dalam Permainan Bolabasket Pemain Harus memiliki kondisi fisik serta Kesegaran Jasmani Yang baik. Untuk itu penjagaan kondisi fisik pemain Bolabasket UKM Teknokrat indonesia hendaknya meliputi latihan kelenturan, latihan lari cepat berulang-ulang untuk meningkatkan kemampuan anaerobik, sesi latihan lari secara terus menerus untuk meningkatkan kemampuan jantung dan latihan kekuatan untuk mengembangkan system otot dan tulang. 


\section{METODE}

\section{Populasi dan Sampel}

Dalam setiap penelitian, populasi yang dipilih erat kaitannya dengan masalah yang ingin diteliti, populasi adalah obyek/subyek yang mempunyai kualitas dan karakteristik tertentu yang ditetapkan oleh peneliti untuk dipelajari dan ditarik kesimpulan (Sugiono, 2012). Berdasarkan pengertian penelitian di atas maka populasi dalam penelitian ini adalah semua anggota UKM Bolabasket Universitas Teknokrat Indonesia yang berjumlah 30 orang.

\section{Teknik Pengumpulan Data}

Data yang diperoleh oleh peneliti melalui tes dan pengukuran terhadap variable yang terdapat dalam penelitian berupa : Kecepatan, Kekuatan, dan Daya Tahan Aerobic (VO2max).

\section{Metode Analisis}

Metode yang digunakan pada penelitian ini ialah metode penelitian deskriptif. Menurut Sugiyono (2012) penelitian deskriptif yaitu, penelitian yang dilakukan untuk mengetahui nilai variabel mandiri, baik satu variabel atau lebih (independen) tanpa membuat perbandingan, atau menghubungkan dengan variabel yang lain. Pada penelitian ini nantinya akan digambarkan tentang kondisi fisik anggota UKM Bolabasket Universitas Teknokrat Indonesia.

\section{HASIL DAN PEMBAHASAN}

Secara keseluruhan, diperoleh nilai maksimum sebesar 19 dan nilai minimum 11. Rata-rata diperoleh sebesar 16 dan standar deviasi sebesar 2,45. Median diperoleh sebesar 17 dan modus sebesar 17. Selanjutnya data akan disusun dalam distribusi frekuensi sesuai dengan rumus yang ditentukan, yang terbagi menjadi lima kategori yaitu baik sekali, baik, cukup, kurang, dan kurang sekali.

Tabel 1. Klasifikasi Urutan Ranking Tes TKJI

\begin{tabular}{lclll}
\hline No & Jumlah Nilai & \multicolumn{1}{c}{ Klasifikasi } & Frekuensi & \multicolumn{1}{c}{ Persentase \% } \\
\hline 1 & $22-25$ & Baik Sekali (BS) & 0 & $0 \%$ \\
\hline 2 & $18-21$ & Baik (B) & 8 & $17,24 \%$ \\
\hline 3 & $14-17$ & Sedang (S) & 16 & $68,96 \%$ \\
\hline 4 & $10-13$ & Kurang (K) & 6 & $13,79 \%$ \\
\hline 5 & $5-9$ & Kurang Sekali (KS) & 0 & $0 \%$ \\
\hline
\end{tabular}

\section{Tes Lari 60 Meter/Kecepatan}

Hasil analisis data dari indikator kecepatan lari 60m berdasarkan perhitungan Tes Kesegaran Jasmani Indonesia (TKJI) diperoleh data yang berbentuk nilai, kemudian dikategorikan menjadi kategori yaitu baik sekali, baik, sedang, kurang, dan kurang sekali. Berikut adalah tabel distribusi frekuensi tingkat kesegaran jasmani anggota UKM Bolabasket Universitas Teknokrat Indonesia berdasarkan Tes lari 60 meter, sebagai berikut :

Tabel 2. Hasil Tes Lari 60 Meter

\begin{tabular}{|c|c|c|c|c|}
\hline No & Skor & Klasifikasi & Frekuensi & Persentase \% \\
\hline 1 & $<7,2$ " & Baik Sekali (BS) & 0 & $0 \%$ \\
\hline 2 & $7,3^{\prime \prime}-8,3^{\prime}$ & Baik (B) & 3 & $10 \%$ \\
\hline 3 & $8,4 "-9,6 "$ & Sedang $(\mathrm{S})$ & 24 & $80 \%$ \\
\hline 4 & $9,7 "-11,0 "$ & Kurang (K) & 3 & $10 \%$ \\
\hline \multirow[t]{2}{*}{5} & $>11,1 "$ & Kurang Sekali (KS) & 0 & $0 \%$ \\
\hline & & Total & 30 & $100 \%$ \\
\hline
\end{tabular}

Berdasarkan tabel ,diperoleh bahwa 0 Anggota (0\%) mempunyai kecepatan lari kurang sekali, 3 Anggota (10 \%) mempunyai kecepatan lari kurang, 24 Anggota (80\%) mempunyai kecepatan lari Sedang , 3 Anggota (10\%) mempunyai kecepatan lari baik dan 0 Anggota (0\%) mempunyai kecepatan lari baik sekali.. Sehingga dapat disimpulkan bahwa tingkat kesegaran jasmani anggota UKM Bolabasket Universitas Teknokrat Indonesia berdasar tes lari 60 meter mempunyai hasil tes yang berbeda. Jadi dapat disimpulkan bahwa Sebagian 
besar kemampuan lari 60 meter yang dimiliki oleh Anggota UKM Bolabasket Universitas Teknokrat Indonesia adalah kategori sedang.

\section{Tes Pull Up/Kekuatan}

Dari Hasil analisis data dari indikator Pull Up berdasarkan perhitungan Tes Kesegaran Jasmani Indonesia (TKJI) diperoleh data yang berbentuk nilai, kemudian dikategorikan menjadi lima kategori yaitu baik sekali, baik, sedang, kurang, dan kurang sekali. Berikut tabel distribusi frekuensi tingkat kesegaran jasmani anggota UKM Bolabasket Universitas Teknokrat Indonesia berdasarkan Tes Pull Up, sebagai berikut :

Tabel 3. Hasil Tes Pull Up

\begin{tabular}{cclcc}
\hline No & Skor & \multicolumn{1}{c}{ Klasifikasi } & Frekuensi & Persentase \% \\
\hline 1 & $>19$ & Baik Sekali (BS) & 0 & 0 \\
\hline 2 & $14-18$ & Baik (B) & 14 & $46,7 \%$ \\
\hline 3 & $9-13$ & Sedang (S) & 12 & $40,0 \%$ \\
\hline 4 & $5-8$ & Kurang (K) & 4 & $13,3 \%$ \\
\hline 5 & $<4$ & Kurang Sekali (KS) & 0 & 0 \\
\hline & Total & 30 & $100 \%$ \\
\hline
\end{tabular}

\section{Tes Sit Up/Kekuatan}

Dari Hasil analisis data dari indikator Sit $U p$ berdasarkan perhitungan Tes Kesegaran Jasmani Indonesia (TKJI) diperoleh data yang berbentuk nilai, kemudian dikategorikan menjadi kategori yaitu baik sekali, baik, sedang, kurang, dan kurang sekali. Berikut tabel distribusi frekuensi tingkat kesegaran jasmani anggota UKM Bolabasket Universitas Teknokrat Indonesia berdasarkan tes Sit Up, sebagai berikut :

Tabel 4. Hasil Tes Sit Up

\begin{tabular}{cclcc}
\hline No & Skor & \multicolumn{1}{c}{ Klasifikasi } & Frekuensi & Persentase \% \\
\hline 1 & $>41$ & Baik Sekali (BS) & 0 & $0 \%$ \\
\hline 2 & $30-40$ & Baik (B) & 2 & $6,7 \%$ \\
\hline 3 & $21-30$ & Sedang (S) & 13 & $43,3 \%$ \\
\hline 4 & $10-20$ & Kurang (K) & 13 & $43,3 \%$ \\
\hline 5 & $<9$ & Kurang Sekali (KS) & 2 & $6,7 \%$ \\
\hline & Total & 30 & $100 \%$ \\
\hline
\end{tabular}

\section{Tes Vertical Jump/Kekuatan}

Dari Hasil analisis data dari indikator Vertical Jump berdasarkan perhitungan Tes Kesegaran Jasmani Indonesia (TKJI) diperoleh data yang berbentuk nilai, kemudian dikategorikan menjadi kategori yaitu baik sekali, baik, sedang, kurang, dan kurang sekali. Berikut tabel distribusi frekuensi tingkat kesegaran jasmani anggota UKM Bolabasket Universitas Teknokrat Indonesia berdasarkan Tes Vertical Jump, sebagai berikut :

\section{Tabel 5.Hasil Tes Vertikal Jump}

\begin{tabular}{cclcc}
\hline No & Skor & \multicolumn{1}{c}{ Klasifikasi } & Frekuensi & Persentase \% \\
\hline 1 & $>73$ & Baik Sekali (BS) & 0 & 0 \\
\hline 2 & $60-72$ & Baik (B) & 9 & $30,0 \%$ \\
\hline 3 & $50-59$ & Sedang (S) & 20 & $66,7 \%$ \\
\hline 4 & $39-49$ & Kurang (K) & 1 & $3,3 \%$ \\
\hline 5 & $<38$ & Kurang Sekali (KS) & 0 & 0 \\
\hline & Total & 30 & $100 \%$ \\
\hline
\end{tabular}

\section{Tes lari 1,2 KM/Daya Tahan (VO2max)}

Hasil analisis data dari indikator lari 1,2 KM berdasarkan perhitungan Tes Kesegaran Jasmani Indonesia (TKJI) diperoleh data yang berbentuk nilai, kemudian dikategorikan menjadi kategori yaitu baik sekali, baik, sedang, kurang, dan kurang sekali. Berikut tabel distribusi frekuensi tingkat kesegaran jasmani anggota UKM Bolabasket Universitas Teknokrat Indonesia berdasarkan Tes Lari 1,2 KM, sebagai berikut : 
Tabel 7. Hasil Tes Lari 1,2 KM

\begin{tabular}{cclcc}
\hline No & Skor & \multicolumn{1}{c}{ Klasifikasi } & Frekuensi & Persentase \% \\
\hline 1 & $<3,14 "$ & Baik Sekali (BS) & 2 & $6,7 \%$ \\
\hline 2 & $3,15 "-4,25 ”$ & Baik (B) & 8 & $26,7 \%$ \\
\hline 3 & $4,26 "-5,12 ”$ & Sedang (S) & 14 & $6,7 \%$ \\
\hline 4 & $5,13 "-6,33 ”$ & Kurang (K) & 6 & $6,7 \%$ \\
\hline 5 & $>6,34$ & Kurang Sekali (KS) & 0 & 0 \\
\hline & Total & 30 & $100 \%$ \\
\hline
\end{tabular}

\section{Pembahasan}

Melihat hasil Tingkat Kesegaran Jasmani Anggota UKM Bolabasket Universitas Teknokrat Indonesia secara keseluruhan menunjukkan pengembangan Tingkat kondisi masih belum maksimal. Kemungkinan disebabkan oleh beberapa faktor salah satu diantaranya adalah pelaksanaan latihan. Pemain sebaiknya diberikan program latihan disesuaikan dengan tujuan yaitu untuk meningkatkan kualitas Tingkat Kesegaran Jasmani yang dimiliki oleh pemain. contohnya latihan yang bertujuan untuk meningkatkan kecepatan lari pemain maka program latihan yang dibuat adalah lari dengan waktu yang singkat. Jika latihan tidak di sesuaikan dengan tujuan makatujuan latihan tersebut tidak akan tercapai tepat untuk masing-masing komponen tingkat kesegaran jasmani yang masih tergolong kurang. Faktor lainnya yang juga akan mempengaruhi tingkat kesegaran jasmani anggota UKM Bolabasket tersebut antara lain : kurangnya beraktifitas jasmani atau latihan diluar jam latihan. Karena dengan Melakukan kegiatan fisik dan olahraga secara baik, teratur dan terus menerus bermanfaat dalam mencapai status kesegaran jasmani yang optimal. Dengan menambah latihan individu maka tubuh juga akan memiliki cukup daya dan akan terlatih dengan baik. Latihan yang baik dan benar akan memberikan pengaruh yang besar pada tiap komponen tubuh dari setiap anggota.dengan pola latihan yang baik dan benar secara tidak langsung akan mempermudah setiap anggota dalam menjalani latihan lutin yang biasanya berat untuk dijalani. Pola hidup dan lingkungan yang kurang sehat juga berpengaruh. Dengan pola hidup sehat akan berpengaruh terhadap kesegaran jasmani. Kesehatan badan juga dipengaruhi oleh lingkungan yang ada disekitar, baik lingkungan fisik dan lingkungan mental dan sosial. Kebiasaan dalam kegiatan sehari-hari yang kurang pengawasan dari orang tua dalam menjaga kesehatan pribadi, juga lingkungan tempat tinggal yang kurang layak. Banyak anggota yang terpengaruh kedalam lingkungan sosial yang kurang baik seperti begadang, merokok dan minuman keras sehingga akan berpengaruh terhadap Kesegaran Jasmani dari anggota tersebut.

Untuk mendapatkan kesegaran jasmani yang baik, dibutuhkan antara lain makanan dan gizi, tidur dan istirahat, latihan jasmani dan olahraga, kebiasaan hidup sehat serta lingkungan yang sehat (Moeloek, 1984). Dengan kesadaran akan menjaga kesehatan tubuh masing masing tentunya bagian lain untuk mempertahankan Kesegaran Jasmani sebagai pemainatau atlet. Makanan yang sehat akan bisa dengan mudah dicerna oleh tubuh. Fungsi anatmis dan fisiologi tubuh akan lebih mudah bekerja. Karena makanan yang sehat akan memberikan pasokan energi yang baik. Dengan energi yang baik tersebut makan takaran dari energi tubuh yang diperlukan oleh tubuh sehingga bagian terkecil dari tubuh seperti otot dan jaringan akan selalu siap. Karena setiap sel, jaringan dan otot merupakan penyusun dari setiap anggota tubuh. Kebiasan lain yang sering dilakukan oleh insan olahraga atau atlet yakni tidur larut. Kurangnya tidur tentunya akan sangat merugikan tubuh. Karena tubuh yang sudah terlatih akan menjadi hilang tenaganya saat atlet tersebut begadang. Terlalu sering tidur larut akan membebani tubuh, karena bagian tubuh yang seharusnya bisa diistirahatkan akan bekerja ekstra. Selanjutnya pendapat lain mengemukakan bahwa seseorang dikatakan memiliki kesegaran jasmani apabila orang tersebut mempunyai kekuatan, kemampuan, kesangguan, dan daya tahan untuk melakukan pekerjaannya dengan efisien, tanpa menimbulkan kelelahan yang berarti yaitu sehabis bekerja atau melakukan aktifitas, masih mempunyai cadangan tenaga serta masih dapat menikmati waktu dengan baik (Kosasih, 1981).

\section{SIMPULAN}

Berdasarkan dari hasil penelitian dan pembahasan tersebut , maka dapat simpulkan : Tingkat Kesegaran Jasmani Anggota UKM Bolabasket Universitas Teknokrat Indonesia, nampak bahwa dari 30 sampel anggota UKM ternyata yang diklasifikasikan baik sebanyak 8 orang $(17,24 \%)$, klasifikasi sedang sebanyak 16 orang $(68,96 \%)$, dan klasifikasi kurang sebanyak 6 orang $(13,79 \%)$, dan tidak ada siswa yang memiliki klasifikasi baik sekali dan kurang sekali. Dengan demikian, hasil tes tingkat kesegaran jasmani pada Anggota UKM Bolabasket Universitas Teknokrat Indonesia dapat dikategorikan sedang. Hal ini disebabkan karena kurangnya aktifitas yang menunjang dalam menjaga Kesegaran Jasmani seperti kegiatan latihan individu, juga faktor kebersihan, aktifitas olahraga lain, makanan, kebiasaan dan pola hidup serta keadaan lingkungan hidup. 


\section{DAFTAR PUSTAKA}

Cholik, Mutohir, dan Gusril. (2004). Perkembangan motorik pada masa anak- anak. Jakarta : Depdiknas.

Dinata, Marta (2006). Bola Basket. Jakarta: Cerdas Jaya.

Fahrizqi, Eko Bagus. (2018). Hubungan Panjang Tungkai, Power Tungkai Dan Koordinasi Mata-Kaki Dengan Kemampuan Passing Pada Pemain Unit Kegiatan Mahasiswa Olahraga Futsal Perguruan Tinggi Teknokrat. Journal of S.P.O.R.T 2. (1). 32-43

Giriwijoyo, S. dkk. (2007). Ilmu Kesehatan Olahraga. Bandung: FPOK UPI

Gumantan, Aditya. Mahfud, Imam (2018). Perbandingan Latihan Dengan Menggunakan Bola Ukuran 4 Dan 5 Terhadap Ketepatan Menendang Bola Ke Arah Gawang. Journal of S.P.O.R.T. 2 (1). 1-7

Kosasih, Engkos, (1981), Olahraga dan Kesehatan. BPK Gunung Mulia, Jakarta

Lutan. Rusli (1991). Belajar Keterampilan, Pengantar Teori dan Metode. Jakarta: Depdikbud

Mahfud, Imam. Fahrizqi, Eko Bagus .(2020) Pengembangan Model Latihan Keterampilan Motorik Melalui Olahraga Tradisional Untuk Siswa Sekolah Dasar. Sport Science And Education Journal.1(1). 31-37

Moeloek D, Tjokronegoro (1984). Dasar Fisiologi Kesegaran Jasmani dan Latihan Fisik, Kesehatan dan Olahraga Universitas Indonesia, Jakarta.

Nugroho, Reza Adhi. Gumantan, Aditya. (2020).Pengaruh Latihan Plyometric Terhadap Peningkatan Kemampuan Vertical Jump Peserta Ekstrakurikuler Bolabasket Sman 1 Pagelaran. Sport Science And Education Journal Universitas Teknokrat Indonesia. 1(1). 1-12

PERBASI. (2008). Peraturan Permainan Bola Basket. Jakarta: PB Perbasi

Sugiyono. (2012). Metode Penelitian Kuantitatif Kualitatif dan R\&D. Bandung: Alfabeta.

Sodikun, Imam. (1992). Olahraga Pilihan Bola Basket. Jakarta: PPLPTK Dirjen Dikti Depdikbud.

Wissel, Hal. (2000). Bola Basket: Dilengkapi dengan Program Pemahiran Teknik dan Taktik. Jakarta: PT RajaGrafindo Persada

Yuliandra, Rizki. (2018). Pengembangan Model Latihan Jump Shoot Bola Basket. Journal of S.P.O.R.T. 2(1). 51-55

\section{BIOGRAFI PENULIS}

\begin{tabular}{|c|c|}
\hline & $\begin{array}{l}\text { Adityo Pratama } \\
\text { Setelah menyelesaikan Pendidikan Sekolah Menengah di MAN } 1 \text { Bandarlampung } \\
\text { tahun 2017. Melanjutkan Pendidikan Strata } 1 \text { di Universitas Teknokrat Indonesia } \\
\text { dengan mengambil Program Studi Pendidikan Olahraga Angkatan 2017. Aktif } \\
\text { sebagai kapten tim sepakbola Universitas Teknokrat Indonesia dan Menjadi pemain } \\
\text { Semen Padang U-18 tahun 2019. Penulis dapat dihubungi melalui Email : } \\
\text { teyoadit@gmail.com }\end{array}$ \\
\hline & $\begin{array}{l}\text { Rizki Yuliandra, M.Pd } \\
\text { Menyelesaikan pendidikan Program Sarjana (Strata -1) pada Fakultas Keguruan } \\
\text { dan Ilmu Pendidikan dengan Program Studi Pendidikan Jasmani dan Kesehatan } \\
\text { (2009-2013) di Universitas Lampung, kemudian melanjutkan Program Pascasarjana } \\
\text { Magister Pendidikan (Strata-2) pada Program Pasca Sarjana Universitas Negeri } \\
\text { Jakarta dengan mengambil Program Studi Pendidikan Olahraga (2013-2015). } \\
\text { Penulis aktif dalam organisasi PERBASI Provinsi Lampung dan Menjadi Bagian } \\
\text { Dari Tim Pelatih PON } 2018 \text { di Jawa Barat. Menjabat Wakil Dekan } 3 \text { Fakultas } \\
\text { Sastra dan Ilmu Pendidikan serta pengajar pada pada Program Studi Pendidikan } \\
\begin{array}{l}\text { Olahraga (2016-Sekarang). Penulis dapat dihubungi melalui email: } \\
\text { rizki.yuliandra@teknokrat.ac.id }\end{array}\end{array}$ \\
\hline
\end{tabular}

